\title{
Preventing COVID-19 in low- and middle-income countries
}

\author{
Sitaram Khadka ${ }^{1,2}$. Furqan K. Hashmi ${ }^{2}$. Muhammad Usman ${ }^{3}$
}

Published online: 13 April 2020

(c) Springer Nature Switzerland AG 2020

\section{Introduction}

Coronavirus disease 2019 (COVID-19) is an infectious disease caused by the previously unidentified severe acute respiratory syndrome coronavirus-2 (SARS-CoV-2) that first appeared as an outbreak in Wuhan, China, in December 2019. According to a recent structural analysis, the virus probably originated in bats and transmitted to humans after mutation in the spike glycoprotein and nucleocapsid protein. It was then transmitted from human to human [1].

COVID-19 is characterized by respiratory illness with flulike symptoms such as dry cough, fever, fatigue, shortness of breath and, in more severe cases, pneumonia, acute respiratory syndrome and death [2]. The World Health Organization (WHO) declared the outbreak a pandemic on 11 March 2020 because $>118,000$ cases had been reported in 110 countries with a sustained risk of further global spread [2]. At the time of writing (26 March 2020), 416,686 COVID19 cases, with 18,589 total deaths, had been reported in 196 countries [3].

The WHO COVID-19 incident management team and other related organizations are actively engaged in providing support and coordination around the preparedness for, mitigation of, response to and recovery from this pandemic [4]. As COVID-19 is a viral infection, and no medicines or vaccines have yet been developed, prevention of virus transmission is crucial, and confirmed cases may require treatment of symptoms.

Developed countries have greater expertise in the investigation and management of such cases than do low- and

Sitaram Khadka

sitaramkhadka5693@gmail.com

1 Shree Birendra Hospital; Nepalese Army Institute of Health Sciences, Kathmandu, Nepal

2 Punjab University College of Pharmacy, University of the Punjab, Lahore, Pakistan

3 University of Veterinary and Animal Sciences, Lahore, Pakistan middle-income countries (LMICs). LMICs are likely to be heavily burdened by COVID-19 because of a lack of awareness, compliance, financial status, infrastructure, human resource and expertise. Therefore, LMICs must prioritize science-based preventive measures in the pre-crisis phase and science-based treatment and counseling during and after the crisis.

\section{Better management of COVID-19}

Viruses are more difficult to deal with than other microorganisms, so preventive measures are the best way to protect people from COVID-19. Whereas developed countries are facing serious problems in the prevention and management of COVID-19, LMICs are even more vulnerable. Local, national and international organizations and healthcare institutions must take the utmost care to protect people from this serious infection.

Following dispersal by a sneeze or cough, droplets containing the coronavirus are airborne. A recent analysis reported that the virus remained active in such a state for up to $3 \mathrm{~h}$ when artificially nebulized as an aerosol [5]. Therefore, preventive measures for this infectious disease include regular hand washing; cleaning with soap and water or sanitizer, especially after touching a surface in a public place; using masks and gloves; covering the mouth and nose while coughing and sneezing; not touching the face with unclean hands; and social distancing [6]. Consumption of vitamin C, citrus fruits, garlic, ginger, honey with warm water, plenty of fluids, boiled water and gargling with saline water may provide symptomatic relief for the common cold, but no evidence exists for these approaches in the treatment or prevention of COVID-19 [7, 8].

In LMICs, the scarcity of resources is a challenge with regard to education about and the prevention and management of COVID-19. Possible effective measures to prevent a COVID-19 crisis include self-isolation and quarantine of suspected and vulnerable people; setting up isolation wards and intensive care units in hospitals; implementing 
Table 1 Myths versus facts about COVID-19 [7-13]

Myth Fact

Hot weather can kill the virus that causes COVID-19

The COVID-19 virus can be transmitted in areas with hot and humid weather

Hot baths and hand dryers can prevent COVID-19

COVID-19 cannot be prevented by taking a hot bath or using hand dryers

COVID-19 can be transmitted through mosquito bites

Thermal scanners can detect COVID-19

COVID-19 cannot be transmitted through mosquito bites

Thermal scanners can detect fever only; it may take 2-10 days after infection to develop fever

Vaccination against flu and pneumonia can prevent COVID-19

Taking vitamin $\mathrm{C}$, ginger shots (a small drink containing a mixture of ginger, honey and lemon with warm water), gargling with saline water, regular rinsing of nose with saline prevents COVID-19

Only older people and children are vulnerable to COVID-19

Wearing masks can prevent COVID-19

Antibacterials are effective for therapy of COVID-19

Pneumococcal and influenza vaccines do not prevent COVID-19, but may prevent the common flu and pneumonia

Such measures cannot prevent COVID-19, but may help in symptomatic relief from the common cold $[7,8]$

People of all ages can be infected, but geriatric and immunocompromised individuals are more vulnerable

Masks, preferably N95 or surgical masks, together with gloves, frequent hand washing with soap and water, or using alcohol-based sanitizer if outside surfaces have been touched, may help prevent the transmission and spread of the coronavirus [11-13]

COVID-19 is a viral infection, therefore, antibacterials are not effective for treating COVID-19, but are useful for treating secondary bacterial infections

COVID-19 coordination centers in hospitals; educating people about COVID-19 via awareness campaigns, including pamphlets and brochures, preferably in the local language; distributing masks, soap, and hand sanitizer; and sharing information via audiovisual and social media. Myths regarding the spread of COVID-19 are prevalent, so awareness and education schemes should be conducted to provide the public with the scientific facts (Table 1).

\section{Discussion}

A health crisis can happen at any time and have devastating effects that disrupt the normal pattern of existence. Medical preparedness means always being in 'ready go' status. Local healthcare professionals, especially community pharmacists, are easily accessed and trusted by the public. They should be considered "first responders" and trained for such medical emergencies in collaboration with other local and national professionals because a complete team of healthcare and other professionals would be an effective approach to manage such health crises. Although LMICs are challenged by a lack of properly trained healthcare providers, the disease itself, and its financial burden, the prime objectives should be to provide awareness about the disease and improve compliance to prevention and mitigation approaches. Governmental resources and support are mandatory for the long-term effectiveness of prevention and management approaches.

\section{Take home messages}

- Focus on measures that prevent the spread of COVID-19, such as campaigns to raise awareness, disprove myths and induce compliance.

- Recognize that prevention and overall management of such health crises may be more difficult in LMICs than in developed countries.

- Manage the global threat by establishing preparedness and mitigation plans prior to potential health crises, response plans during the crisis, and response and recovery plans after the crisis.

- Ensure the cooperation of healthcare providers and administrative bodies at local, national and global levels.

Author Contributions SK contributed to the concept, literature search and writing the manuscript. FKH and MU contributed to the literature search and guiding the writing of the manuscript.

\section{Compliance with Ethical Standards}

Funding No sources of funding were used to prepare this manuscript.

Conflict of interest SK, FKH, and MU have no conflicts of interest that are directly relevant to the content of this article. 


\section{References}

1. Benvenuto D, Giovanetti M, Ciccozzi A, et al. The 2019-new coronavirus epidemic: evidence for virus evolution. J Med Virol. 2020;92(4):455-9.

2. World Health Organization. Coronavirus; 2020. https://www.who. int/health-topics/coronavirus\#tab=tab_3. Accessed 26 Mar 2020.

3. World Health Organization. Novel coronavirus (COVID-2019) situation; 2020. https://experience.arcgis.com/experience/685d0 ace 521648f8a5beeeee1b9125cd. Accessed 26 Mar 2020.

4. World Health Organization. Coronavirus disease 2019 (COVID19) situation report - 56. 2020. https://www.who.int/docs/defau lt-source/coronaviruse/situation-reports/20200316-sitrep-56-covid -19.pdf?sfvrsn=9fda7db2_6. Accessed 26 Mar 2020.

5. van Doremalen N, Bushmaker T, Morris D, et al. Aerosol and surface stability of $\mathrm{HCoV}-19$ (SARS-CoV-2) compared to SARSCoV-1. N Engl J Med. 2020. https://doi.org/10.1056/NEJMc 200497320201

6. World Health Organization. Coronavirus; 2020. https://www.who. int/health-topics/coronavirus\#tab=tab_2. Accessed 26 Mar 2020.

7. Bucher $\mathrm{A}$, White $\mathrm{N}$. Vitamin $\mathrm{C}$ in the prevention and treatment of the common cold. Am J Lifestyle Med. 2016;10(3):181-3.
8. Can vitamin C intake ward off coronavirus? 2020. https://gulfn ews.com/uae/health/can-vitamin-c-intake-ward-off-coronaviru s-1.70122799\#. Accessed 26 Mar 2020.

9. World Health Organization. Coronavirus disease (COVID-19) advice for the public: myth busters; 2020. https://www.who.int/ emergencies/diseases/novel-coronavirus-2019/advice-for-public/ myth-busters. Accessed 26 Mar 2020

10. Kaushal J, Gupta MC, Jindal P, et al. Self-medication patterns and drug use behavior in housewives belonging to the middle income group in a city in northern India. Indian J Commun Med Off Publ Indian Assoc Prev Soc Med. 2012;37(1):16.

11. Centers for Disease Control and Prevention. Preventing the spread of coronavirus disease 2019 in homes and residential communities; 2020. https://www.cdc.gov/coronavirus/2019-ncov/hcp/guida nce-prevent-spread.html. Accessed 26 Mar 2020.

12. van der Sande M, Teunis P, Sabel R. Professional and home-made face masks reduce exposure to respiratory infections among the general population. PLoS ONE. 2008;3(7):e2618.

13. Healthline. Can face masks protect you from the 2019 coronavirus? What types, when and how to use. 2020. https://www.healt hline.com/health/coronavirus-mask. Accessed 26 Mar 2020. 